\title{
Caracterização da atividade antioxidante, teor de fenóis totais e atividade larvicida frente ao Aedes aegypti de Citrus sinensis L. (Laranja)
}

\author{
Emanuel Isaias Mota Araujo* (Licenciado em Química, bolsista ATP-B (CNPq)); \\ Láiza Cristina Carlos Freire Monteiro (Licenciada em Química, bolsista ATP-B (CNPq)); \\ Alídna Mosana Souza de Oliveira (Licenciada em Química, Bolsista DTI-C (CNPq)); \\ Leonardo Alacântara Alves (Professor do Campus Apodi - Instituto Federal do Rio Grande do \\ Norte); \\ Luciana Medeiros Bertini (Professor do Campus Apodi - Instituto Federal do Rio Grande do \\ Norte) \\ * isaias_desbrava@hotmail.com;
}

resumo:

Os produtos naturais são utilizados pela humanidade desde tempos imemoriais. Além de técnicas medicinais, muitos venenos foram descobertos na natureza e utilizados para fins de defesa. A história do Brasil está intimamente ligada ao comércio de produtos naturais. A laranja é o fruto produzido pela laranjeira (Citrus sinensis), uma árvore pertencente à família Rutaceae e ajuda a reduzir o risco de certos tipos de câncer, ataques do coração. O presente trabalho teve como objetivo determinar a atividade antioxidante, o teor de fenóis e a atividade lanvicida frente ao Aedes aegypti dos extratos da Laranja. O extrato que apresentou melhor atividade antioxidante e teor de fenóis foi o em etanol, e no que diz respeito à atividade larvicida nenhum dos extratos apresentaram atividade.

\section{palavras-chave:}

Citrus sinensis, produtos naturais; Atividade lanvicida. 


\section{I NTRODUÇÃO}

A história do Brasil está intimamente ligada ao comércio de produtos naturais (as especiarias), os quais determinaram as várias disputas de posse da nova terra e, por fim, a colonização portuguesa (VIEGAS Jr., BOLZANI, 2006).

No Brasil, as plantas cítricas foram introduzidas pelos primeiros colonizadores, plantadas inicialmente na Bahia, tendo fácil adaptação às condições climáticas do país, obtendo-se maiores rendimentos na produção e cultivos que os apresentados na Europa.

A laranja é o fruto produzido pela laranjeira (Citrus sinensis), uma árvore pertencente à família Rutaceae, gênero Citrus, espécie sinensis. A laranja é um fruto híbrido, criado na antigüidade a partir do cruzamento do pomelo (Citrus maxima) com a tangerina (Citrus reticulata) (MATTOS JÚNIOR et al., 2005).

Esta fruta é um produto de importância para a agricultura e a economia brasileira. O Brasil é responsável por quase 90 \% das laranjas produzidas na América do Sul, o que corresponde a 34 \% da produção mundial desta fruta (TRIBESS; TADINI, 2001).

Os cítricos, bem como seus produtos derivados têm impactos benéficos sobre a saúde humana e por isso, frutas cítricas têm atraído muita atenção por causa de suas propriedades nutricionais e antioxidantes (DEL CARO et al., 2004).

Diante do exposto, este trabalho tem como objetivo determinar a atividade larvicida, antioxidante e teor de fenóis totais dos extratos (em etanol e água) das folhas de Citrus sinensis L. (laranja).

\section{REVI SÃO BI BLI OGRÁFI CA}

Os produtos naturais são utilizados pela humanidade desde tempos imemoriais. A busca por alívio e cura de doenças pela ingestão de ervas e folhas talvez tenha sido uma das primeiras formas de utilização dos produtos naturais (VIEGAS Jr., BOLZANI, 2006). Na Idade Antiga, além de técnicas medicinais, muitos venenos foram descobertos na natureza e utilizados para fins de defesa, caça e mesmo ilícitos, como a utilização do veneno de Hemlock (Conium maculatum) na execução de prisioneiros, inclusive Sócrates, durante o Império Grego (DEWICK, 1996).

O Brasil é o país com a maior diversidade genética vegetal do mundo, contando com mais de 55.000 espécies catalogadas de um total estimado de 350.000 a 550.000 espécies. A diversidade biológica vegetal brasileira não é conhecida com precisão tal a sua complexidade, estimando-se a existência de mais de dois milhões de espécies distintas de plantas, animais e microrganismos (NODARI; GUERRA, 2003).

Em média, uma laranja contém cerca de $70 \mathrm{mg}$ de vitamina $\mathrm{C}$, quantidade superior as necessidades diárias de um adulto. A vitamina C é um antioxidante que protege as células contra danos causados pelos radicais livres e ajuda a reduzir o risco de certos tipos de câncer, ataques do coração, derrames cerebrais e outras doenças. A parte fibrosa da laranja é um grande estimulador do funcionamento intestinal (RGNUTRI, 2015).

Os antioxidantes são formados por diferentes grupos químicos, apresentando diferentes estruturas e propriedades (DÍAZ-REINOSO et al., 2006). As frutas cítricas, dentre estas a laranja, contém compostos bioativos como limonóides, flavonóides, pectinas, cumarinas e furanocumarinas e antioxidantes conhecidos, como a vitamina $\mathrm{C}$ e carotenóides, os quais apresentam diversos benefícios à saúde. Baseado em estudos laboratoriais, os flavonóides cítricos e limonóides apresentam propriedades de proteção contra uma variedade de doenças crônicas, como arterosclerose e câncer. Os flavonóis, flavanóis, antocianinas e fenilpropanóides podem atuar como antioxidantes e, por diversos mecanismos, atuar como compostos cardioprotetores (JAYAPRAKASHA; GIRENNAVAR; PATIL, 2008).

Nos últimos anos tem crescido a busca por extratos vegetais e substâncias naturais que sejam efetivas no combate ao mosquito adulto e às larvas de Aedes aegypti que não tragam danos à saúde ou ao meio ambiente, isso por que tais insetos têm apresentado resistência aos inseticidas sintéticos (SIMAS et al., 2004). Alguns estudos apontam compostos de origem botânica com atividade larvicida e potencial para uso no controle de vetores (CARVALHO; SILVA, 2000). 


\section{METODOLOGIA}

\subsection{Coleta do material vegetal}

O material vegetal (folhas) de Citrus sinensis foi coletado na cidade de Apodi no sítio Baixa fechada I, no mês de janeiro do ano de 2015 pela manhã.

\subsection{Preparação dos extratos em etanol e água}

Após a coleta do material vegetal (folhas) de C. sinensis, foi colocada em contato com etanol por 7 dias. Após esse período, foi realizada a filtração para que o líquido fosse colocado num sistema de rota evaporador sob pressão reduzida para obtenção do extrato em etanol. Em seguida, repetiu-se o mesmo processo fazendo uso da água como solvente, após filtração realizou-se a concentração do extrato através da evaporação em banho-maria.

\subsection{Atividade antioxidante pelo método do 2,2-difenil-1-picrilhidrazil (DPPH)}

Os testes para verificar a atividade antioxidante e encontrar a concentração que inibe 50\% dos radicais $\left(\mathrm{CI}_{50}\right)$ dos extratos foram realizados com uma solução em metanol de DPPH a $60 \mu \mathrm{M}$. Foram preparadas diferentes concentrações com os extratos (5000, 1000, 500, 200, 150, 100, 50 e 10 ppm), retirada uma alíquota de $1 \mathrm{~mL}$ e acrescentado $1 \mathrm{~mL}$ de DPPH. Após 30 minutos foram feitas as leituras no espectrofotômetro a $520 \mathrm{~nm}$. O mesmo procedimento foi realizado com o controle positivo o TROLOX. Os resultados obtidos após a leitura foram analisados em um programa de estatística (Origin 7.0) (ALMEIDA et. al, 2010).

\subsection{Determinação do teor de fenóis totais}

O teste para verificação dos fenóis totais foi feito pelo método de Folin-Cicalteau. Cada extrato vegetal foi dissolvido em metanol, em seguida transferido para um balão volumétrico de $100 \mathrm{~mL}$ e completado com solvente. Em outro balão, de $50 \mathrm{~mL}$, foram transferidos 7,5 mL da solução inicial, esta segunda solução teve seu volume novamente acertado com metanol. Uma alíquota de $100 \mu \mathrm{L}$ desta última solução foi agitada com $500 \mu \mathrm{L}$ do reagente de Folin-Ciocalteu e $6 \mathrm{~mL}$ de água destilada por 1 min. Após esse período foi adicionado $2 \mathrm{~mL}$ de $\mathrm{Na}_{2} \mathrm{CO}_{3} 15 \%$ a mistura foi agitada por 30 s. A solução teve seu volume acertado para $10 \mathrm{~mL}$ com água destilada. Esperou-se 2 h, e em seguida a absorbância das amostras foram medidas no espectrofotômetro a $750 \mathrm{~nm}$, fazendo uso de cubetas de quartzo (BONOLI et al., 2004). A quantificação dos compostos fenólicos nos extratos foi realizada em triplicata e os resultados foram expressos em equivalentes de ácido gálico (GAE) por grama de extrato bruto.

\subsection{Determinação da atividade lanvicida}

Inicialmente foram colocadas as cartelas dos ovos do Aedes aegypti cedidas pela Secretaria de Saúde do Estado do Ceará para eclodir. Quando as larvas atingiram o $3^{\circ}$ estagio, foram realizados os testes. Foi preparada uma solução mãe dos extratos a 1000 ppm, utilizando 0,1 g de extrato, 3 mL de dimetilsulfóxido (DMSO) e $97 \mathrm{~mL}$ de água da torneira. Em seguida, foram retiradas alíquotas desta solução para obter as concentrações menores (500, 250, 100, 50 e 10ppm) e transferidas para um béquer. Em seguida, cada amostra teve seu volume acertado para $20 \mathrm{~mL}$ e o volume acrescentado continha 25 larvas do $3^{\circ}$ estágio do Aedes aegypti. Após um período de $72 \mathrm{~h}$ a leitura foi realizada e observada o número de larvas mortas.

\section{RESULTADOS E DISCUSSÕES}

Após a aplicação do método de extração, e concentração dos extratos, os mesmos foram pesados e seus rendimentos foram calculados, o mesmos podem ser observados na Tabela abaixo. 
Tabela 1: Rendimento dos extratos das folhas de $C$. sinensis.

\begin{tabular}{c|c}
\hline Extrato & Rendimento percentual \\
\hline Etanol & $9,11 \%$ \\
Água & $2,56 \%$ \\
\hline
\end{tabular}

Aplicou-se o método do sequestro do radical DPPH, e obteve-se a concentração capaz de inibir $50 \%$ do radical $\left(\mathrm{IC}_{50}\right.$ ) dos extratos (em etanol e água) das folhas de $C$. sinensis, os resultados podem ser observados na Tabela 2.

Tabela 2: $\mathrm{CI}_{50}$ dos extratos das folhas de $C$. sinensis.

\begin{tabular}{c|c}
\hline Extrato & $\mathrm{CI}_{50}(\mathrm{ppm})$ \\
\hline Etanol & 138,49 \\
Água & 482,9 \\
& \\
TROLOX* & 4 \\
\hline
\end{tabular}

$(*)=$ Padrão positivo.

Pode-se observar que o extrato em etanol apresentou uma melhor atividade antioxidante, com uma $\mathrm{CI}_{50}$ menor, porém este valor ainda é muito alto quando comparado ao TROLOX, que foi o padrão utilizado para comparação. Isto pode ser explicado pelo fato de que o padrão é uma substância isolada, enquanto o extrato é composto por várias substâncias, podendo ocasionar interferência na ação dos compostos antioxidantes presentes nesta mistura.

Foram realizados também testes para determinação do teor de fenóis totais, que são substâncias conhecidas por serem bons antioxidantes, os resultados obtidos podem ser observados na Tabela 3.

Tabela 3: Teor de fenóis totais dos extratos das folhas de C. sinensis.

\begin{tabular}{c|c}
\hline Extrato & $\begin{array}{c}\text { Fenóis totais (mg EAG/g } \\
\text { de extrato bruto) }\end{array}$ \\
\hline Etanol & 21,79 \\
Água & 4,25 \\
\hline
\end{tabular}

O extrato que apresentou o maior teor de fenóis, como já era esperado, foi o extrato em etanol, e tal fato explica a boa atividade antioxidante apresentada por este extrato.

Por fim foram realizados os testes para determinação da atividade larvicida dos extratos, nas Tabelas 4 e 5 é possível observar as médias de larvas mortas em cada uma das concentrações nas quais realizaram-se os testes.

Tabela 4: Média de larvas mortas em cada uma das amostras do extrato em etanol.

\begin{tabular}{c|c}
\hline $\begin{array}{c}\text { Concentração } \\
(\mathrm{ppm})\end{array}$ & $\begin{array}{c}\text { Média de larvas } \\
\text { mortas }\end{array}$ \\
\hline 500 & 4 \\
250 & 2 \\
\hline
\end{tabular}




\begin{tabular}{c|c}
\hline 100 & 3 \\
50 & 3 \\
\hline
\end{tabular}

Tabela 5: Média de larvas mortas em cada uma das amostras do extrato em água.

\begin{tabular}{c|c}
\hline $\begin{array}{c}\text { Concentração } \\
\text { (ppm) }\end{array}$ & $\begin{array}{c}\text { Média de larvas } \\
\text { mortas }\end{array}$ \\
\hline 500 & 0 \\
250 & 0 \\
100 & 0 \\
50 & 0 \\
\hline
\end{tabular}

Como não houve variação no número de larvas mortas, não foi possível aplicar os dados no programa para que se pudesse calcular a concentração capaz de matar $50 \%$ da população das larvas $\left(C L_{50}\right)$, significando que nenhum dos extratos da laranja apresentou atividade larvicida.

\section{CONCLUSÃO}

Os estudos realizados proporcionaram a caracterização de algumas propriedades importantes dos extratos das folhas de $C$. sinensis, tais como: atividade antioxidante, atividade larvicida e teor de fenóis totais. Ambos os extratos não apresentaram atividade larvicida, e nos demais parâmetros o extrato em etanol merece destaque, uma vez que apresentou os melhores resultados.

\section{Characterization of antioxidant activity, total phenolic content and larvicidal activity against Aedes aegypti of Citrus sinensis L. (Orange)}

\section{Abstract:}

Natural products are used by mankind since time immemorial. In addition to medical techniques, many poisons have been found in nature and used for defense purposes. The history of Brazil is closely linked to trade in natural products. Orange is the fruit produced by orange (Citrus sinensis), a tree belonging to the Rutaceae family and helps reduce the risk of certain cancers, heart attacks. This study aimed to determine the antioxidant activity, phenolic content and larvicidal activity against the Aedes aegypti of orange extracts. The extract showed better antioxidant activity and phenol content was in ethanol, and with regard to the activity of the extracts showed no larvicidal activity.

Keywords: Citrus sinensis; natural products; larvicidal activity.

\section{Referências bibliográficas}

ALMEIDA, M. C. S.; ALVES, L. A.; SOUZA, L. G. S.; MACHADO, L. L.; MATOS, M. C.; OLIVEIRA, M. C. F.; LEMOS, T. L. G.; BRAZ-FILHO. Flavonoids and other substances from Lippia sidoides and their antioxidant activities. Química Nova, v. 33, p.1877-1881, 2010.

BONOLI, M.; VERARDO, V.; MARCONI, E.; CABONI, M. F. Antioxidant Phenols in Barley (HordeumvulgareL.) Flour: Comparative Spectrophotometric Study Among Extraction Methods of Free and Bound Phenolic Compounds. Journal of Agricultural and Food Chemistry, vol. 52, p. 5195, 2004.

CARVALHO, L. A. F.; SILVA I. G. Avaliação longitudinal da atividade do temephós a 1\% sobre o Aedes aegypti (Lin,1762). Entomologia y Vectores. 7:191-201, 2000. 
DEL CARO A., PIGA A., VACCA V., AGABBIO M. Mudanças de flavonóides, vitamina C e capacidade antioxidante em segmentos de cítricos minimamente processadas e sucos durante 0 armazenamento. Food Chemistry. 2004, v. 84, p. 99-105.

DEWICK, P. M.; Medicinal natural products: a biosynthetic approach. John Wiley \& Sons: New York, 1997.

DÍAZ-REINOSO, B.; MOURE, A.; DOMÍNGUES, H.; PARAJÓ, J. C. Supercritical CO2 extraction and purification of compounds with antioxidant activity. Food Chemistry, v. 54, p. 2441-69, 2006.

JAYAPRAKASHA, G. K.; GIRENNAVAR, B.; PATIL, B. S. Antioxidant capacity of pummelo and navel oranges: Extraction efficiency of solvents in sequence. $L W T$, v. 41, p. 376-84, 2008.

MATTOS JÚNIOR, D.; DE NEGRI, J. D.; FIGUEIREDO, J. O.; POMPEU JÚNIOR, J. Citros: principais informações e recomendações de cultivo. 2005.

NODARI, R. O.; GUERRA, M. P. Aspectos genéticos e moleculares da produção vegetal. In:

Farmacognosia: da Planta ao Medicamento, 5.ed., 2003, Porto Alegre/Florianópolis, Ed. UFRGS/Ed. UFSC, 2003. p. 29-43.

$\begin{array}{lllll}\text { RGNUTRI. Identidade } & \text { e } & \text { nutrição. } & \text { Disponível }\end{array}$ em<http://www.rgnutri.com.br/alimentos/propriedades/laranja.php>. Acesso em: setembro 2015.

SIMAS, N. K.; LIMA, E. C.; CONCEIÇÃO, S. R.; KUSTER, R. M.; OLIVEIRA FILHO, A. M. Produtos naturais para o controle da transmissão da dengue: atividade larvicida de Myroxylon balsamum (óleo vermelho) e de terpenídes e penilterpenóides. Química Nova, v. 27, n. 01, p. 46-49, fev. 2004.

TRIBESS, T.B.; TADINI, C.C. Suco de laranja natural minimamente processado: uma alternativa para ampliar o mercado de suco de laranja no Brasil. 2001.

VIEGAS Jr, C.; BOLZANI, V. S. Os produtos naturais e a química medicinal moderna. Química Nova, v.29, p. 326-337, 2006. 